\title{
MYCOREMEDIATION OF SOIL CONTAMINATED WITH CADMIUM AND LEAD BY Trichoderma sp.
}

\begin{abstract}
Conducted research determined the effect of the Trichoderma fungi on the presence of cadmium and lead ions in the soil contaminated by mentioned elements. The aim of the study was to demonstrate whether the fungi of this kind can contribute to remediation of soil by the immobilization of heavy metals. Experiments were conducted in laboratory conditions. The vaccine containing spores of Trichoderma asperellum was introduced into the soil contaminated with cadmium and lead by direct injection. Analyses of the soluble fraction of selected heavy metals were performed after 3 and 15 days of cultivation using atomic absorption spectrometry (AAS). Statistical significant positive effects on the immobilization of lead ions and no statistical differences in inhibition of cadmium translocation were observed. The results showed that Trichoderma fungi are suited to support the process of environment remediation by removal of lead. This suggests possible application of Trichoderma asperellum in mycoremediation and supporting role in phytoremediation of soil.
\end{abstract}

Keywords: mycoremediation, Trichoderma sp., heavy metals, biological plant protection

\section{Introduction}

Natural environment is balanced by the circulation of chemical elements. However, the existing stability between its release and re-bond in the geological formations is often disturbed by human activity. Due to combustion of coals, liquid fuels, substances and raw material processing, large amounts of gaseous pollutants and dust are introduced into the atmosphere, soil and water. It is common that they contain heavy metals. The term heavy metals is determined for metallic elements whose density is greater than $5 \mathrm{~g} / \mathrm{cm}^{3}$. These include the biogenic elements such as zinc, copper or manganese and those that do not carry any biological functions like cadmium, lead or mercury. Even small concentration of the last group has a negative impact on a number of biological processes occurring in living organisms and soil [1]. These pollutants have become a serious problem all over the world [2] because they have a long-lasting negative impact on ecosystems, including soil and biological processes occurring in it $[3,4]$. They cause dysfunction of vital functions in plants, animals and soil microorganisms and the level of elements toxicity depends on their concentration, biochemical role they play in metabolism and the specific chemical elements interactions of synergistic or antagonistic type. The great importance is the availability of chemical element described by its ability to move from soil solution to living organisms. Significant role in the transformation of soil substances play microorganisms, they are

\footnotetext{
${ }^{1}$ Faculty of Science \& Technology, Jan Dlugosz University in Czestochowa, al. Armii Krajowej 13/15, 42-200 Częstochowa, Poland, phone +48 343612179 int. 148

*Corresponding author: kbandurska@hotmail.com
} 
responsible for the circulation of substances, maintenance of soil structure, detoxification of harmful chemicals. Moreover, microorganisms control the activity of plant pests and influence plants growth [5-9].

Very valuable for the homeostasis of ecosystems are all factors causing immobilization of heavy metal ions such as cadmium or lead in order to prevent penetration of soil and plant structures by them.

Heavy metals are indestructible and removable only in a very small degree. Most often, once introduced into the environment they circulate constantly, changing only the form and type of chemical bonds. Exceeding normal concentration of heavy metals in the soil affects type and intensity of biological processes in the soil [1].

Plants together with water and minerals actively take from the soil heavy metals such as zinc, cadmium, lead and mercury. The negative role of heavy metal ions on plant growth and development depends not only on their concentration in the soil, but also on a number of factors that may affect the transport of minerals from the soil to the roots, such as the content of organic compounds in the soil, soil structure and $\mathrm{pH}$. Particularly important are biotic factors, such as bacteria and fungi, which significantly limit the translocation of heavy metals. Mushrooms have a number of mechanisms that allow to reduce the ecological stress caused by heavy metals. These are extracellular mechanisms, such as precipitation, chelation and binding with the cell wall as well intracellular ones, such as binding of metals with organic acids, sulfur compounds, polyphosphates, peptides, as well transport of these chemical elements to cellular compartments [10]. Some of these mechanisms function constitutively, while others are induced by excessive concentrations of metals in the cytoplasm [11]. In addition, part of the detoxification process is an antioxidant system that allows fungi to counteract the accumulation of reactive oxygen species [10-13]. Extracellular mechanisms are designed to protect cells from metals entering into the cytoplasm, while intracellular mechanisms are used to neutralise the harmful effects of metals in the cytosol [10]. Thanks to the mentioned mechanisms, fungi not only protect their own cells, but by entering into symbiotic relationships, they are able to reduce the toxic effect of heavy metals in the host plant $[14,15]$. Numerous reports show that zinc, cadmium and lead are filtered by symbiotic mycorrhizal fungi [12, 13, 16-18].

Unfortunately, there is little information about whether other fungi living in the rhizosphere of plant roots may have importance in the immobilization of heavy metals. It would be particularly valuable in relation to the saprophytic fungi such as Trichoderma, which are artificially introduced, with great success starting from 30's of XX century [19], into the soil in order to protect plants against pathogens. Fungi of this type are potent antagonists of parasitic microorganisms belonging to genus: Rhizoctonia, Phytophthora, Pythium, Fusarium, Alternaria, Sclerotinia, Sclerotium, Gaeumannomyces, Thielaviopsis, Verticillium, Botrytis and numerous bacteria and viruses [20, 21]. Currently Trichoderma spp. is one of the most popular types of fungi used on the market as plant growth-promoting fungi (PGPF) [22] and as components in the plant protection products [5, 23, 24]. It is also important that these fungi never attack plants and even stimulate their growth and resistance [6]. The increased interest in mentioned fungi also stems from the fact that they are very widespread in nature and capable of adaptation in different environments. Moreover, they are easy to isolate and culture in artificial conditions where they grow rapidly and produce a lot of conidia and often chlamydospores. Most of the research work about Trichoderma indicate their antagonism towards pathogenic fungi inhabiting root systems [5, 7, 23]. 
The aim of this study was to determine whether popular in biological crop protection fungi of type Trichoderma are able to immobilise and inhibit translocation of selected heavy metals and thus may be helpful in mycoremediation of soil. The working hypothesis assumes that saprophytic fungi accumulate heavy metals in their structures, inhibiting their movement from soil to plants. Cadmium and lead were selected for experimental studies because, as shown in the literature, there is a large difference in the mobility of these elements in plants and animal tissues [25, 26]. It was interesting whether fungi, which developed multiple protective mechanisms against heavy metals, equally inhibited the mobility of cadmium and lead in the soil. The selection of appropriate microorganisms largely determines the effectiveness of remediation of soils contaminated with heavy metals $[12,14,16,17]$.

\section{Materials and methods}

\section{Description of the experiment}

Established purpose of the research was verified using laboratory tests. The translocation of heavy metals into plants was studied by analysing the total content of cadmium and lead in the soil, and in underground and above-ground parts of pine seedlings (Pinus sylvestris L.). Seedlings were grown under controlled conditions in vase cultures for a period of 4 months. Remediation of fungi from the Trichoderma genus was studied by analysing leachable fraction of heavy metals using classical Tessier extraction methodology [27] and sequential extraction elements [28].

The materials for the study were: pure fungi culture of Trichoderma spores from the laboratory collection of the Faculty of Science \& Technology UJD; peat - soil substrate described by Kawai [29], solutions of lead and cadmium in the form of $\mathrm{Pb}\left(\mathrm{C}_{2} \mathrm{H}_{5} \mathrm{COO}\right)_{2}$ and $\mathrm{CdCl}_{2}$ respectively.

Fungi were grown on agar described by Bandurska et al. [30]. In the next step water-containing vaccine containing $1,9 \cdot 10^{4} \mathrm{CFU} / \mathrm{mL}$ spores of Trichoderma was prepared (Fig. 1).

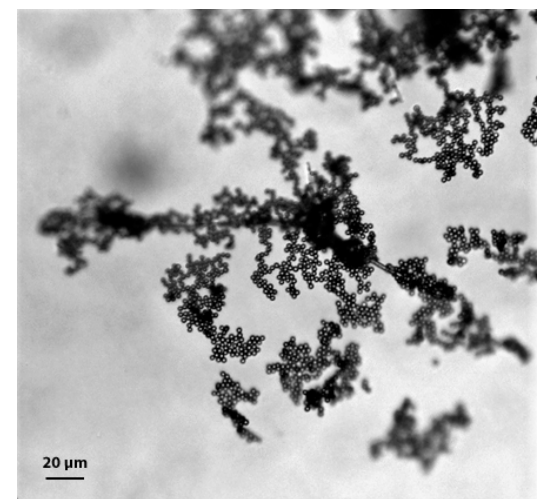

Fig. 1. Microscopic image of the vaccine content (photo taken by P. Krupa)

In the experiment, by addition of heavy metal salts, used modified Kawai substrate [29]. It was sterilised in an autoclave at $121^{\circ} \mathrm{C}$ for 30 minutes. The pot experiment was 
conducted in $100 \mathrm{~mL}$ containers in triplicate in the following variants: 1) the substrate contaminated with cadmium, 2) the substrate contaminated with lead, 3) the substrate contaminated with cadmium with addition of Trichoderma asperellum spores, 4) the substrate contaminated with lead with addition of Trichoderma asperellum spores and 5) control substrate without additives. Lead (variant 2 and 4) and cadmium (variant 1 and 3) was added at concentration of $3000 \mu \mathrm{g} \mathrm{Pb} / \mathrm{g}$ as a $\mathrm{Pb}\left(\mathrm{C}_{2} \mathrm{H}_{5} \mathrm{COO}\right)_{2}$ and $300 \mu \mathrm{g} \mathrm{Cd} / \mathrm{g}$ as a $\mathrm{CdCl}_{2}$. Solution of fungus spores $(10 \mathrm{~mL})$ was introduced into 100 grams of substrate in variant 3 and 4 . The addition of metals was followed by growth tests of the mycelium culture on an agar medium checking the maximum concentration of cadmium and lead at which mycelium develops. At the final stage of substrate preparation, the $\mathrm{pH}$ was adjusted to 6.5. The experiment with plants was carried out in $200 \mathrm{~mL}$ containers in triplicate for each variant of the experiment (variants the same as in the soil experiment). After a 4-month growing period, the seedlings were removed from the substrate, mechanically divided into underground and above-ground parts. The samples were brought to dry weight, separately wet mineralised in a microwave mineraliser and subjected to atomic absorption spectrometry (AAS) analysis for heavy metal content. Results were given in micrograms per gram of dry plant biomass. The LOD for lead and cadmium were $0.4 \mathrm{ppm}$ and $0.1 \mathrm{ppm}$ respectively, and the LOQ were $1.3 \mathrm{ppm}$ and $0.5 \mathrm{ppm}$ respectively.

\section{Determination of $\mathrm{pH}$ of soils}

Determination of $\mathrm{pH}$ of soil was performed according to the Polish Standard PN-ISO 10390:1997 [31]. Samples of $10 \mathrm{~g}$ of air-dry soil were transferred to a $50 \mathrm{~mL}$ capacity glass beaker and added $25 \mathrm{~mL}$ of deionised water. Content was mixed and left for 24 hours. After that time measurements of $\mathrm{pH}$ were conducted.

\section{The total content of heavy metals}

The total heavy metal content was marked according to the methodology proposed by Sastre et al. [32]. In order to determine the total content of the investigated heavy metals, wet mineralization of the studied soils and individual elements of plant biomass was carried out by using a microwave oven. To dishes called "teflon bombs" $0.25 \mathrm{~g}$ of the studied soils were added, previously grated in an agate mortar and sieved through a $0.1 \mathrm{~mm}$ sieve. Then $8 \mathrm{~mL}$ of $65 \% \mathrm{HNO}_{3}$ and $2 \mathrm{~mL}$ of $30 \% \mathrm{H}_{2} \mathrm{O}_{2}$ were added. After mineralization of sample it was filtered through a hard paper filter into $50 \mathrm{~mL}$ graduated flasks and made up to volume with deionised water. The mineralization of each sample was carried out in triplicate. The research on the content of trace elements was carried out using the AAS method.

\section{Determination of water leachable heavy metals content}

In order to determine the leaching of tested heavy metals, soil extracts were prepared. Weighted portions of soil (10 grams) were placed in $250 \mathrm{~mL}$ flasks. To the samples $100 \mathrm{~mL}$ of deionised water ( $\mathrm{pH}$ adjusted to 7.0) was added. The flasks were shaken for 1 hour using laboratory shaker. In the next step samples were leached (with $1 \mathrm{M} \mathrm{MgCl}_{2} ; \mathrm{pH}=7.0$ ) for 12 hours at $25{ }^{\circ} \mathrm{C}$ with shaking. This part of experiment was performed on the $3^{\text {rd }}$ and $15^{\text {th }}$ day after the introduction of cadmium chloride and lead acetate solutions to the substrate. Collected samples were filtered 4 times using filter paper, then the filtrates were subjected for further analysis. Determination of heavy metals concentration was performed by AAS (Unicam Solaar 939) at a wavelength of $232 \mathrm{~nm}$. 


\section{Statistics}

The results were presented as mean \pm standard deviation $(S D)$. The significance of differences was tested using U Mann-Whitney test and Wilcoxon test for independent and dependent data, respectively. The value of $p<0.05$ was considered to be statistically significant. The statistical analysis was performed with STATISTICA 12.0 (Stat-Soft Poland Sp. z o.o., Krakow, Poland).

\section{Results}

In the experiments leachable lead and cadmium content were analysed. It showed strong sorption of heavy metals in the soil (control of lead and cadmium content after 3 and 15 days) (Figs. 2a and 3a). The concentration of lead ions after 3 days decreased from $3000.0 \mu \mathrm{g} / \mathrm{g}$ to $163.6 \mu \mathrm{g} / \mathrm{g}(p<0.001)$ and after 15 days did not cause significant quantitative changes in the elution of metal ions $(p=0.051)$ (Fig. 2a). The concentration of cadmium ions after 3 days of incubation was reduced from 300.0 to $6.9 \mu \mathrm{g} / \mathrm{g}$ $(p<0.001)$. Incubation during 15 day increased the sorption of the mentioned metal by the magnitude of 10 to $0.6 \mu \mathrm{g} / \mathrm{g}(p<0.001)$ (Fig. 3a).

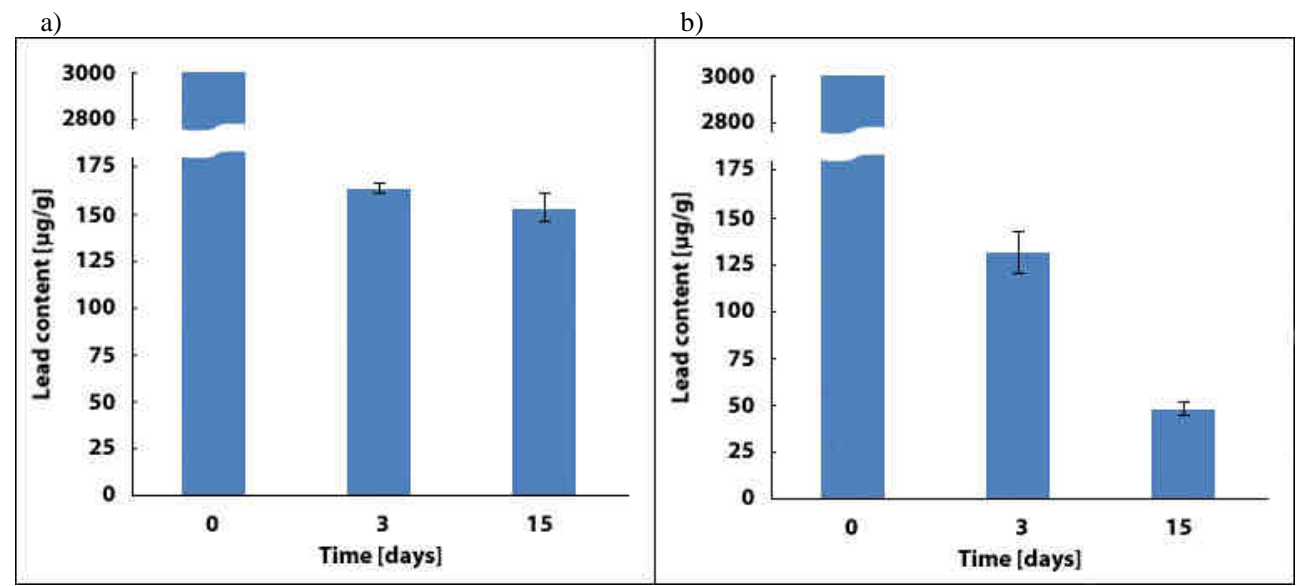

Fig. 2. The average content of lead in: a) the control sample and b) the sample with addition of Trichoderma vaccine, after 3 and 15 days in the contaminated soil. Mean $\pm S D$

A statistically significant was immobilization of heavy metals between the $3^{\text {rd }}$ and $15^{\text {th }}$ day growth period of the fungus Trichoderma in the culture medium (Fig. $2 b$ and $3 b$ ). The concentration of lead ions decreased from 3000.0 to $130.9 \mu \mathrm{g} / \mathrm{g}$ on day 3 $(p<0.001)$ and $48.0 \mu \mathrm{g} / \mathrm{g}$ on day 15 of incubation $(p<0.001)$ (Fig. 2b). A statistically significant difference in lead concentration between the samples containing the Trichoderma and the control samples without the presence of the fungus after 15 days of incubation $(p=0.012)$ was observed (Fig. 2). The concentration of cadmium ions after 3 days of incubation was reduced from 300.0 to $7.3 \mu \mathrm{g} / \mathrm{g}(p<0.001)$. Incubation during 15 days increased the sorption of the cadmium metal ions by the magnitude of 10 to $0.8 \mu \mathrm{g} / \mathrm{g}(p<0.001)$ (Fig. 3b). 
a)

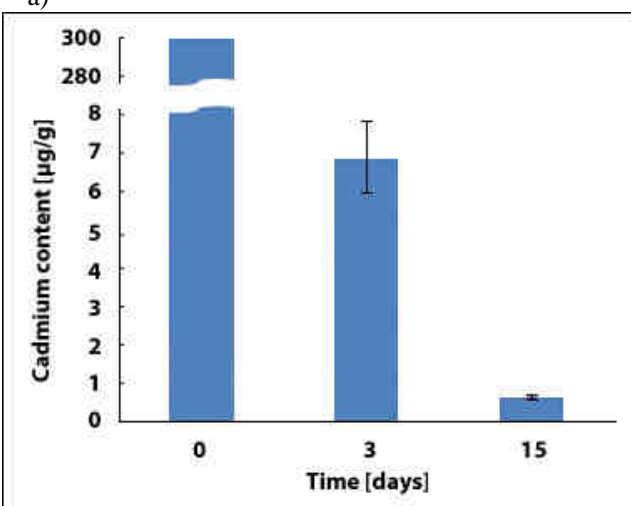

b)



Fig. 3. The average content of cadmium in: a) the control sample and b) the sample with addition of Trichoderma vaccine, after 3 and 15 days in the contaminated soil. Mean $\pm S D$

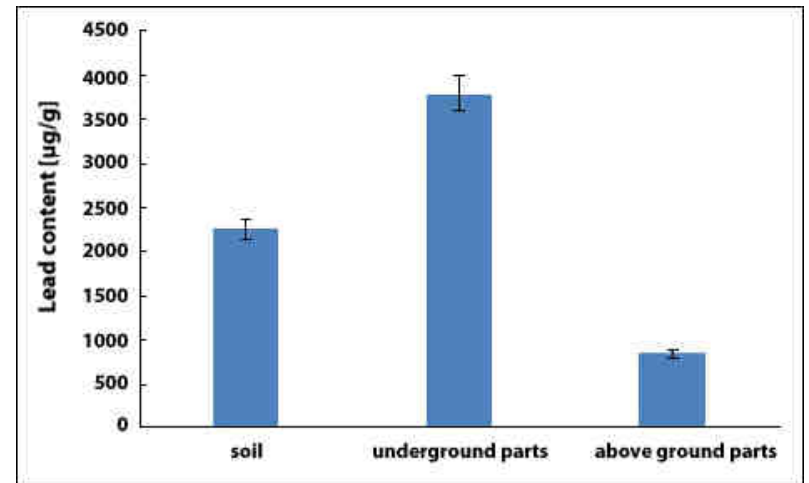

Fig. 4. The average content of lead in the soil and pine seedlings. Mean $\pm S D$

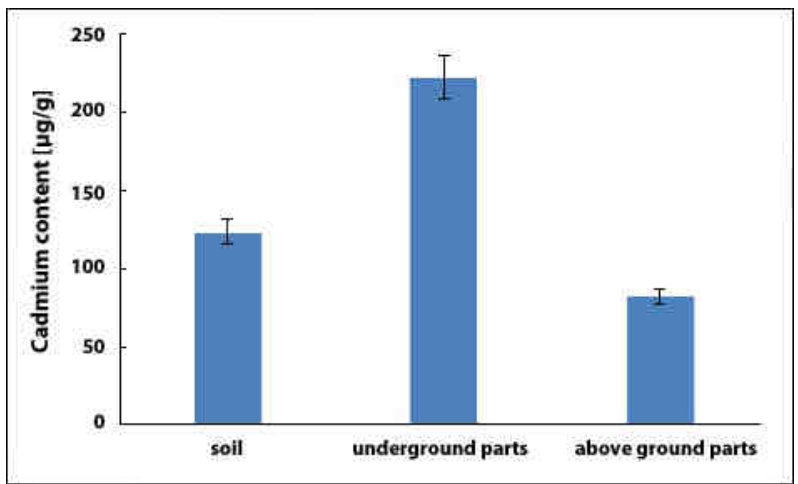

Fig. 5. The average content of cadmium in the soil and pine seedlings. Mean $\pm S D$ 
After 4 months growing period in both cases for lead and cadmium, the metal content was much higher in the underground parts of plants compared to the above-ground parts (lead: $3800.0 \mu \mathrm{g} / \mathrm{g}$ of dry mass and $850.0 \mu \mathrm{g} / \mathrm{g}$ of dry mass; cadmium: $222.2 \mu \mathrm{g} / \mathrm{g}$ of dry mass and $82.3 \mu \mathrm{g} / \mathrm{g}$ of dry mass, respectively) (Figs. 4 and 5).

\section{Discussion}

The content of heavy metals in soils exposed to industrial emissions is examined for a long time $[11,12,16]$. However, mostly total content of heavy metals is reported in the literature. Although it is a potentially dangerous threat, metals in this system are largely immobilised and thus harmless at this moment [33]. Plants get mainly soluble fractions, so it is important to understand the factors determining heavy metals immobilization. There may be many different causes for inhibition of heavy metals translocation, for example fractions of clay, humic and structural substances of soil. This reaction can be seen by analysing Figures 4 and 5 where the values of cadmium and lead in the substrate are smaller than those introduced in the solution, despite the examination of their total content. Probably some of the compounds are chelated into structures that even the nitric acid used in the analysis does not wash out. Weakening toxicity of heavy metals in relation to plants is also caused by binding of ions through structures and compounds produced by microorganisms, storage in vesicles, precipitation of ions outside the cells, modification of plant metabolism. Examples are glomalines produced by fungi belonging to glycoproteins and forming soil aggregates $[12,13,16,17]$. Due to their high durability and degradation resistance, they show high stability in the environment [34]. Reduction of metal toxicity is also carried out on the principle of ions binding in the chitin of the fungal cell wall and accumulation in vacuoles $[16,17]$. The results of this study confirmed mentioned thesis (Figs. 2 and 3). On the 3rd day of heavy metals introduction into the substrate, there was significant drop of both lead and cadmium. Statistically insignificant at this stage of sorption was the addition of spores of the fungus Trichoderma (Figs. 2b and 3b). Analyzing the results of the total metal content (Figs. 4 and 5), we can observe the existence of a clear barrier inhibiting the translocation of metals at the root-shoot location. It consists of both the structural elements of the root and the fungi located on its surface.

There is little literature data on the remediation of heavy metals by the fungus belonging to Trichoderma species and existing data mainly relate to the aquatic environment. For example, Holda and Kisielowska showed effective removal of $\mathrm{Cr}(\mathrm{IV})$ from aqueous solutions by Trichoderma viride arising from intracellular bioaccumulation [35]. On the other hand, Ali and Hashem [8] studying water of Nile contaminated with zinc, cadmium and lead showed that binding of these metals by fungi largely depends on the temperature. Confirmation of the effectiveness of cadmium and lead intake by the fungus belonging to Trichoderma species is described by Sahu et al. [9]. They demonstrated high efficiency binding of heavy metals by fungi, which coincides with the results of this study, of relatively small remediation of cadmium. Analysing results from Figure $3 \mathrm{~b}$ the difference in concentration of cadmium ions between 3rd and 15th day of incubation is not statistically significant. While the clear differences were recorded in concentrations of lead ions (Fig. 2b) in samples containing Trichoderma spores an average of three times decrease in value was noted. Confirmation of this trend can be found in the work described by Kacprzak et al. [36] who noted the positive phytoextraction factor of heavy metals except for lead which was immobilised by the influence of fungi. 
In recent years, the results of this study bring on a new cognitive aspect, valuable in the light of dynamically growing biological technologies such as bioremediation of hardly renewable soil. Outcomes demonstrate the potential of using fungi in the process of assisted phytoextraction next to chelating agents. Trichoderma fungi on one hand can strengthen growth potential of plants in stressful conditions carrying out the process of phytoextraction and on the other hand they can contribute to effective introduction of cadmium in the root system. In the case of other technology - phytostabilisation, besides Trichoderma fungi protection of plants from pathogens, and growth enhancement, they might be factors which greatly decelerate the efficacy of heavy metals translocation (for example lead). Each mentioned technological process must be preceded by a thorough biological examination of the certain fungus strain in terms of heavy metals stabilization.

\section{Conclusion}

Taking into account the results of research related to mycoremediation of heavy metals by fungi belonging to Trichoderma species, it can be stated that they are perfectly suited to assist in removal of environmental contaminants such as lead. The application in the field, however, must be preceded by basic research because in the light of presented work these fungi may immobilise heavy metals to varying degree. Results of conducted experiments indicate that the fungi belonging to Trichoderma species accumulate and limit the translocation of lead.

\section{References}

[1] Charlesworth S, De Miguel E, Ordóńez A. A review of the distribution of particulate trace elements in urban terrestrial environments and its application to considerations of risk. Environ Geochem Health. 2011;33:103-23. DOI: 10.1007/s10653-010-9325-7.

[2] Cui Y, Zhu YG, Zhai R, Huang Y, Qiu Y, Liang J. Exposure to metal mixtures and human health impacts in a co tami $\square$ ated area $\mathrm{i} \square \mathrm{Na} \square \mathrm{i} \square \mathrm{g}$, Chi $\square$ a. E $\square$ viro $\square \mathrm{I} \square$ t. 2005;31(6):784-90. DOI: 10.1016/j.envint.2005.05.025.

[3] Majer BJ, Tscherko D, Paschke A, Wennrich R, Kundi M, Kandeler E, et al. Effects of heavy metal contamination of soils on micronucleus induction in Tradescantia and on microbial enzyme activities: a comparative $\mathrm{i} \backsim$ vestigatio $\square$ Mutat Res. 2002;515:111-24. DOI: 10.1016/s1383-5718(02)00004-9.

[4] Pérez-de-Mora A, Madejón E, Burgos P, Cabrera F. Trace element availability and plant growth in a mine-spill contaminated soil under assisted natural remediation I. Soils. Sci Total Environ. 2006;363(1-3):28-37. DOI: 10.1016/j.scitotenv.2005.10.015.

[5] Khalil M. Efficiency of Trichoderma viride and Bacillus subtilis as biocontrol agents against root rot caused by Fusarium sola $\triangle \mathrm{i}$ i $\square$ tomato. Egyptia $\square$ J Agric Res. 2019;97:507-16. DOI: 10.21608/ejar.2019.151891.

[6] Saba H, Vibhash D, Manisha M, Prashant KS, Farhan H, Tauseef A. Trichoderma - a promising plant growth stimulator a d bioco trol age $t$. Mycosphere. 2012;3(4):524-31. DOI: 10.5943/mycosphere/3/4/14.

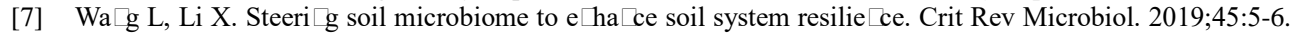
DOI: $10.1080 / 1040841 X .2019 .1700906$.

[8] Ali EH, Hashem M. Removal efficiency of the heavy metals $\mathrm{Zn}$ (II), $\mathrm{Pb}$ (II) and $\mathrm{Cd}$ (II) by Saprolegnia delica and Trichoderma viride at different $\mathrm{pH}$ values and temperature degrees. Mycobiology. 2007;35(3):135-44. DOI: 10.4489/MYCO.2007.35.3.135.

[9] Sahu A, Mandal A, Thakur J, Manna MC, Subba Rao A. Exploring bioaccumulation efficacy of Trichoderma viridae: $\mathrm{A} \square$ alter $\square$ ative bioremediatio $\square$ of cadmium a $\square$ d lead. Natl Acad Sci Lett. 2012;35(4):299-302. DOI: 10.1007/s40009-012-0056-4.

[10] Bellion M, Courbot M, Jacob C, Blaudez D, Chalot M. Extracellular and cellular mechanisms sustaining metal tolerance in ectomycorrhizal fungi. FEMS Microbiol Lett. 2006;254(2):173-81. DOI: 10.1111/j.1574-6968.2005.00044.x.

[11] Colpaert JV, Wevers JH, Krznaric E, Adriaensen K. How metaltolerant ecotypes of ectomycorrhizal fungi protect plants from heavy metal pollution. Annals Forest Sci. 2011;68(1):17-24. DOI: 10.1007/s13595-010-0003-9. 
[12] Luo ZB, Chenhan Wu C, Zhang C, Li H, Lipka U, Polle A. The role of ectomycorrhizas in heavy metal stress tolerance of host plants. Environ Exper Bot. 2014;108:47-62. DOI: 10.1016/j.envexpbot.2013.10.018.

[13] Schlunk I, Krause K, Wirth S, Kothe E. A transporter for abiotic stress and plant metabolite resistance in the ectomycorrhizal fungus Tricholoma vaccinum. Environ Sci Pollut Res Int. 2015;22(24):19384-93. DOI: 10.1007/s11356-014-4044-8.

[14] Schützendübel A, Polle A. Plant responses to abiotic stresses: heavy metal-induced oxidative stress and protection by mycorrhization. J Exp Botany. 2002;53:1351-1365. DOI: 10.1093/jexbot/53.372.1351.

[15] Krupa P, Kozdrój J. Ectomycorrhizal fungi and associated bacteria provide protection against heavy metals in inoculated pine (Pinus sylvestris L.) seedlings. Water Air Soil Pollut. 2007;182:83-90. DOI: 10.1007/s11270-006-9323-7.

[16] Cabała J, Krupa P, Misz-Kennan M. Heavy metals in mycorrhizal rhizospheres contaminated by Zn-Pb mining and smelting around Olkusz in southern Poland. Water Air Soil Pollut. 2009;199:139-49. DOI: 10.1007/s11270-008-9866-X.

[17] Bano SA, Ashfaq D. Role of mycorrhiza to reduce heavy metal stress. Nat Sci. 2013;5(12A):16-20. DOI: 10.4236/ns.2013.512A003.

[18] Bandurska K, Krupa P, Berdowska A, Marczak M. Adaptation of selected ectomycorrhizal fungi to increased concentration of cadmium and lead. Ecol Chem Eng S. 2016;23(3):483-91. DOI: 10.1515/eces-2016-0035.

[19] Weindling R. Trichoderma lignorum as parasite of other soil fungi. Phytopathology. 1932;22:837-45.

[20] Benìtez T, Rincòn AM, Limòn MC, Codòn AC. Biocontrol mechanisms of Trichoderma strains. Int Microbiol. 2004;7(4):249-60. Available from: https://scielo.isciii.es/pdf/im/v7n4/Benitez.pdf.

[21] John RP, Tyagi RD, Prévost D, Brar SK, Pouleur S, Surampalli RY. Mycoparasitic Trichoderma viride as a biocontrol agent against Fusarium oxysporum $\mathrm{f}$. sp. adzuki and Pythium arrhenomanes and as a growth promoter of soybean. Crop Prot. 2010;29(12):1452-9. DOI: 10.1016/j.cropro.2010.08.004.

[22] Chetan K, Sandhya M, Sarma BK, Singh SP, Singh HB. Unraveling the efficient applications of secondary metabolites of various Trichoderma spp. Appl Microbiol Biotechnol. 2014;98:533-44. DOI: 10.1007/s00253-013-5344-5.

[23] Zin NA, Badaluddin NA. Biological functions of Trichoderma spp. for agriculture applications. Ann Agric Sci. 2020;65(2):168-78. DOI: 10.1016/j.aoas.2020.09.003.

[24] Alfano G, Lewis Ivey MLC, Cakir C, Bos JIB, Miller SA, Madden LV, et al. Systemic modulation of gene expression in tomato by Trichoderma hamatum. Phytopathology. 2007;97:429-37. DOI: 10.1094/PHYTO-97-4-0429.

[25] Violante A, Cozzolino V, Perelomo L, Caporale AG, Pigna M. Mobility and bioavailability of heavy metals and metalloids in soil environments. J Soil Sci Plant Nutr. 2010;10(3):268-92. DOI: 10.4067/S0718-95162010000100005.

[26] Tchounwou P, Yedjou C, Patlolla A, Sutton D. Heavy metal toxicity and the environment. In: Luch A, editor. Molecular, Clinical and Environmental Toxicology. Experientia supplementum. Basel: Springer; 2012;101. DOI: 10.1007/978-3-7643-8340-4_6.

[27] Tessier A, Cambell PG, Bisson M. Sequential extraction procedure for the speciation of particulate tracemetals. Anal Chem. 1979;51(7):844-51. DOI: 10.1021/ac50043a017.

[28] Bień J, Chlebowska-Ojrzyńska M, Zabochnicka-Świątek M. Ekstrakcja sekwencyjna w osadach ściekowych (Sequential extraction in sewage sludge). Proc ECOpole. 2011;5(1):173-8. Available from: https://drive.google.com/drive/folders/1tpAJ9F051yIW0vm3j0S6hbzez4q31QeD.

[29] Kawai M. Artifical ectomicorrhiza formation on roots of air-layered Pinus densiflora saplings by inoculaton with Lycophyllum shimeji. Mycologia. 1997;89(2):228-32. DOI: 10.2307/3761075.

[30] Bandurska K, Krupa P, Berdowska A, Jatulewicz I. Use of saprophytic fungi specimens as a plant protection agents in tomatoe plantation. Ecol Eng. 2015;43:88-93. DOI: 10.12912/23920629/58908.

[31] Polish Standard PN-ISO 10390:1997. Soil quality. Determination of pH. Polish Committee for Standardization, Warszawa. Available from: https://sklep.pkn.pl/pn-iso-10390-1997p.html.

[32] Sastre J, Sahuquillo A, Vidal M, Rauret G. Determination of Cd, Cu, $\mathrm{Pb}$ and $\mathrm{Zn}$ in environmental samples: microwave-assisted total digestion versus aqua regia and nitric acid extraction. Anal Chim Acta. 2002; 462(1):59-72. DOI: 10.1016/S0003-2670(02)00307-0.

[33] Ali H, Khan E, Ilahi I. Environmental chemistry and ecotoxicology of hazardous heavy metals: environmental persistence, toxicity, and bioaccumulation. J Chem. 2019;6730305. DOI: $10.1155 / 2019 / 6730305$

[34] Wang S, Wu Q-S, He X-H. Exogenous easily extractable glomalin-related soil protein promotes soil aggregation, relevant soil enzyme activities and plant growth in trifoliate orange. Plant Soil Environ. 2015;61(2):66-71. DOI: 10.17221/833/2014-PSE. 
[35] Holda A, Kisielowska E. Biological removal of $\mathrm{Cr}(\mathrm{VI})$ ions from aqueous solutions by Trichoderma viride. Physicochem Probl Miner Process. 2013;49(1):47-60. DOI: 10.5277/ppmp130105.

[36] Kacprzak M, Rosikoń K, Fijałkowski K, Grobelak A. The effect of Trichoderma on heavy metal mobility and uptake by Miscanthus giganteus, Salix sp., Phalaris arundinacea, and Panicum virgatum. Appl Environ Soil Sci. 2014;506142. DOI: 10.1155/2014/506142. 